\title{
The Use of Human Amniotic Allograft on Osteochondritis Dissecans of the Talar Dome: A Comparison with and without Allografts in Arthroscopically Treated Ankles
}

\author{
J. Joseph Anderson, Zflan Swayzee \\ New Mexico Bone and Joint Institute, Alamogordo, NM, USA \\ Email: josephanderson5@gmail.com
}

Received 13 August 2015; accepted 5 September 2015; published 8 September 2015

Copyright (C) 2015 by authors and Scientific Research Publishing Inc.

This work is licensed under the Creative Commons Attribution International License (CC BY).

http://creativecommons.org/licenses/by/4.0/

(c) (i) Open Access

\section{Abstract}

Arthroscopy of the ankle with micro-fracture technique is one way to initially treat symptomatic talar dome lesions. Human amniotic allograft has been used in similar bone, soft tissue and cartilage defects to aid in healing of tissue using graft cells that have not differentiated into a particular cell line. Patients were taken from the primary surgeon's practice to include those who had undergone arthroscopy with micro-fracture technique for treatment of a talar dome lesion less than $2 \mathrm{~cm}^{2} .101$ patient surgeries were completed arthroscopically without additional major procedures. 54 surgeries were completed with human amniotic allograft; 47 were completed without (control group). Modified ACFAS ankle scores were taken pre-operatively, 3, 12 and 24 months post-operatively. Visual analog pain scores were taken pre-operatively and 24 months post-operatively. Results comparing pre-operative modified ACFAS scores between the control and graft groups were not significantly different $(p=0.14)$. There was a significant improvement in both groups' scores following ankle arthroscopy with micro-fracture as expected. However, the amniotic tissue group did significantly better when comparing the post-operative scores between the control and graft group. Pain scores comparing control and amniotic patient groups were significant $(p<0.001)$ with amniotic allograft patients achieving a greater improvement in pain reduction than the control both early and at 24 months. There were no complications, wound dehiscence or infections recorded. Combining ankle arthroscopy/micro-fracture technique with human amniotic allograft on talar dome lesions, less than $2 \mathrm{~cm}^{2}$, significantly improves the patients' pain and ACFAS scores. 


\section{Keywords}

\section{Bone Lesions, Human Amniotic Allograft, Ankle Arthroscopy, Talus Fractures, Stem Cells, Cartilage Restoration}

\section{Introduction}

Osteochondritis dissecans (OCD) is a general term used for describing cartilaginous full-thickness defects of a joint surface. These osteochondral defects or trans-chondral fracture (TCF) can present acute or sub-acute and present as one of the most challenging conditions to treat in the ankle. As early as 1922, Kappis recognized and described osteo-chondral defects while talar dome fractures were first documented in 1932 by Rendu [1] [2]. Since 1959 when the Bernt and Hardy Classification system was presented, TCF can be categorized and usually attributed to a traumatic event. These kinds of fractures in the ankle can be problematic and difficult to treat, especially when they become symptomatic [3] [4]. A TCF that affects the talar dome is very difficult to treat in that the standard of care for TCFs smaller than $2.5 \mathrm{~cm}^{2}$ has been open or arthroscopic debridement with subchondral drilling or micro-fracture technique to allow fibrocartilage and growth [5]. The authors, having used arthroscopy with micro-fracture technique extensively over many years and found initial results to be good, were looking to improve upon the technique being unsatisfied with patient's two-year outcomes.

Human amniotic allografts (HAA) were first used in a rudimentary form that was unrefined and not completely safe to use. It was used externally with fairly good results to heal burns, ulcers and open wounds to give the skin extra undifferentiated tissue to assist in rapid healing [6]-[11]. HAA were also used on conjunctiva defects of the eye in the early 1930's [12]. Internal use was documented in 1938 by Shimburg with use in the lumbar spine region [13]. Replacement of parietal peritoneum and joints were also among the later uses of HAA with generally good success [14] [15]. Initially there were complications associated with donor disease transmission and tissue application which rendered widespread use to be ineffective or problematic.

Over the last three decades, the technology and knowledge surrounding disease transmission have allowed the use of HAA to be safe and effective for a variety of procedures and medical fields. HAA for bone repair have had excellent success and limited complications associated with modern amniotic allografts. These cells are multipotent and antigenicity has been avoided due to the cells being undifferentiated [16]-[23]. The authors felt that modern HAA tissue in addition to micro-fracture would have more benefit in the healing process of a TCF than those patients who did not receive HAA and were treated with micro-fracture alone.

The authors have used amniotic allograft for other surgery applications and have so far encountered no adverse effects [24] [25]. They have applied it to calcaneal osteotomies with iliac crest grafts, trans-chondral fracture defects of the talus (TCF), tendon ruptures, high-risk fusions and high-risk wounds [24]-[26]. The authors were hopeful that the addition of HAA would improve the outcomes of the injury and assist in the ability to replace the typical fibrocartilage tissue with a greater quality hyaline cartilage [27] [28]. Although TCF of the talar dome is fairly rare compared to other locations and fractures that surround the ankle joint, the authors felt that a comparison of standard technique to the same with HAA was warranted and could assist the body of research surrounding human amniotic allografts.

\section{Patients and Methods}

The patients were chosen retrospectively from the primary author's (JJA) practice from January 2006 to March 2014. There were 832 patients that had an ankle scope to review, 345 of those had lesions less than $2 \mathrm{~cm}^{2}$ on the talar dome. Patients were excluded based on availability of MRI scans, having a solitary and isolated lesion, patients lost to missing data or follow up times and whether the patient had another major surgery such as has peroneal tendon relocation or significant tibial, fibular, or talar exostectomy not done arthroscopically at the same time as the lesion repair. The patient's TCF also had to be reachable via arthroscopy and not composed of a multi-planar shoulder lesion of the talus. This brought the total number included in the study to 101 patients with a talar dome lesion less than $2 \mathrm{~cm}^{2}$. All patients had modified American College of Foot and Ankle Surgeons (ACFAS) scores taken by the medical staff and visual analog scores (VAS) taken by patient indication preoperatively and postoperatively at 3 months, 12 months and 24 months by the physicians and nursing staff. The pa- 
tients had MRI scans of lesions on their talar dome and did not have any other major surgeries at the time of surgically repairing the lesion. The included corresponding surgeries were more distal, minor procedures. All the data statistically analyzed with student's t tests and ANOVA. The control group consisted of 47 patients that had a talar dome lesion less than $2 \mathrm{~cm}^{2}$ in size with no allograft. The HAA group had 54 patients with a talar dome lesion less than $2 \mathrm{~cm}^{2}$ but incorporated a human amniotic allograft to assist in healing and regeneration of cartilage. All patients had to complete mandatory 4 week post-operative physical therapy. All patients were informed that they had a choice to receive a tissue allograft (HAA) and had informed consent regarding surgery, TCF, HAA tissue risks, alternatives and benefits. Patients were not randomized or blinded to the use of HAA. Four patients were not included due to lack of follow-up.

\subsection{Surgical Technique}

Standard medial and lateral portals were used, standardized with a uniform distraction technique. All limbs had thigh tourniquet used at $300 \mathrm{~mm} / \mathrm{hg}$. A pre-emptive proximal ankle block was standardized with all patients. The ankle had an inspection, and then a generalized synovectomy as indicated was done. As needed, a medial to lateral debridement and exostectomy of the anterior lip of the tibia was performed. Care was taken to assure that the tibial-talar interface had no residual kissing lesion remaining. The talar dome lesion was identified and compared to X-ray and MRI size and location (Figure 1). A circumferential debridement was performed to the subchondral level (Figure 2). A micro-fracture awl standard technique was used to perform micro-fracturing of the lesion. When used, liquid form HAA was applied directly to the lesion via needle technique and under direct visualization. Instruments were removed and portals were closed. The patient was then placed in an ankle stirrup splint until first post op visit.

\subsection{Human Amniotic Allograft (HAA) Information}

Human amniotic allograft has been commercially available over the last decade. Several different forms exist and are useful for different procedures and wound applications. The properties are generally the same, all containing
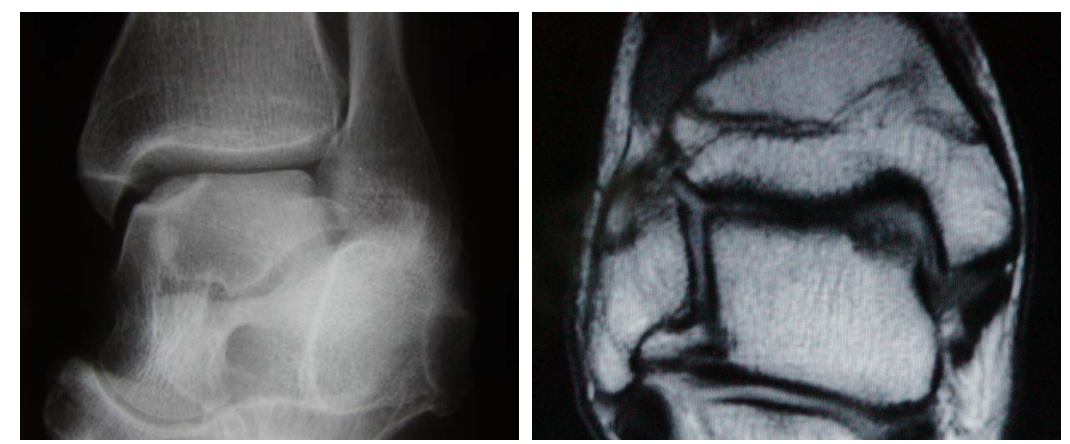

Figure 1. X-ray and MRI of trans-chondral fracture. Trans-chondral fracture of the talar dome in X-ray and MRI.

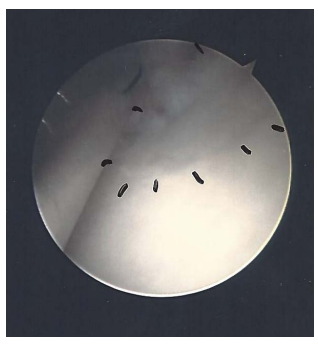

(a)

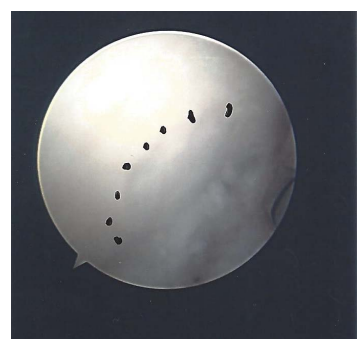

(b)

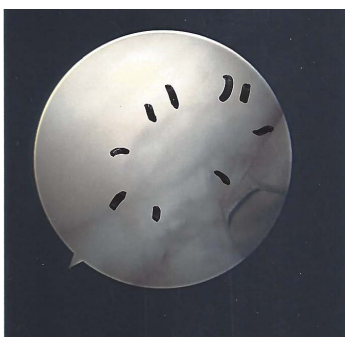

(c)

Figure 2. Arthroscopy images before human amniotic allograft may be applied. Outlining (with dashes) the lesion and the progression of micro-fracture awl technique before HAA is applied. 
multipotential stem cells, growth factors, atrophic proteins, hyaluronic acid, proteoglycans and collagen precursors [29]. There are some differences in live versus non-viable cells and also characteristics based on the contents of amnion and chorion. The process of separating the useful amniotic cells from the whole of the tissue creates a product that is multipotent and immune privileged. The donors are all screened before the tissue is taken to ensure that the safest materials are taken and there is no chance of disease transference. All donors are screened for HIV, hepatitis, HTLV and any other disease deemed necessary before tissue collection.

The specific material used on the author's patient population was a cryopreserved liquid form of amniotic allograft ${ }^{1}$. It contains morselized amniotic membrane as well as other cells in the amniotic fluid of amniotic origin [30]. The product has not been identified to initiate an immune response in any variety of patients inserted into a variety of locations on the body [6] [11] [17] [19] [21] [22]. Bioactivity of HAA has been studied recorded in a few studies to show that is interacting with surrounding tissue [31] [32].

\section{Results}

The average age for the all patients were 46.6 (range 18 - 81), 47.4for the allograft group and 46.0 for the control. There were 55 males (54.46) and 46 females (45.54). The average physical therapy for the control group pre-operatively is 5.0 weeks and 5.7 weeks post-operative. The average for the treatment group is 3.9 weeks preoperatively and 4.6 weeks postoperatively. There were no significant differences between the control and treatment groups' pre-operative and post-operative weeks in physical therapy $(\mathrm{p}=0.011$ pre-operative, $\mathrm{p}=0.08$ post-operative) as shown in Table 1.

The average VAS scores for the control and HAA groups were 5.0 and 5.2 pre-operatively, respectively and 2.5 and 1.2 at 24 months post-operatively, respectively. There is no significant differences between the preoperative VAS scores $(p=0.35)$ but a significant difference in the post-operative VAS scores $(p<0.001)$. There is also significance when comparing the pre and post-operative scores together for the control group and HAA group ( $\mathrm{p}<0.001, \mathrm{p}<0.001$ respectively) as shown in Table 1 .

The ACFAS averages for control and HAA groups were 74.4 and 73.4 for preoperative, 84.7 and 89.5 at 3 months follow up, 86.2 and 91.1 at 12 months follow up and 83.9 and 88.3 at 24 months follow up. The ACFAS scores were not significant between control and HAA pre-operative numbers $(\mathrm{p}=0.293)$ but significant when comparing the control and HAA ACFAS scores at 3 months, 12 months and 24 months post-operatively ( $<$ < 0.001, $\mathrm{p}<0.001, \mathrm{p}<0.001$ respectively) as shown in Table 1 .

The total patient average width of the defect or bone edema from MRI scans was $1.9 \mathrm{~cm}$ but $1.3 \mathrm{~cm}$ intraoperatively. There was an average difference of $0.6 \mathrm{~cm}$ between the MRI and intra-operative size of the defect, with the MRI findings showing larger or equal in all but one case $(\mathrm{p}<0.001)$.

There were two patients in the HAA group, when asked if they would do the procedure again to gauge satisfaction said they would not (1.9\%) and 4 in the control group (4.0\%). There were no complications or revisions needed for the surgery in either group. There were no adverse effects associated with the use of human amniotic

Table 1. Patient demographics with averages and p-values.

\begin{tabular}{|c|c|c|c|c|c|c|c|c|c|}
\hline \multirow[b]{2}{*}{ Average } & \multirow[b]{2}{*}{ Age } & \multicolumn{2}{|c|}{ Physical therapy (weeks) } & \multicolumn{2}{|c|}{ VAS pain score } & \multicolumn{4}{|c|}{ ACFAS score } \\
\hline & & Pre-op & Post-op & Pre-op & $\begin{array}{l}\text { Post-op } \\
\text { (24 months) }\end{array}$ & Pre-op & 3 month & 12 month & 24 month \\
\hline Graft & 47.39 & 3.86 & 4.66 & 5.18 & 1.23 & 73.39 & 89.53 & 91.14 & 88.26 \\
\hline No Graft & 46.01 & 5.09 & 5.74 & 5.02 & 2.48 & 74.39 & 84.7 & 86.19 & 83.93 \\
\hline \multicolumn{10}{|l|}{$p$ values } \\
\hline Comparing* & 0.3517 & 0.082 & 0.011 & 0.353 & $7 \mathrm{E}-6$ & 0.293 & $5 E-8$ & $1 \mathrm{E}-9$ & $4 \mathrm{E}-5$ \\
\hline Graft $^{* *}$ & & & & \multicolumn{2}{|c|}{$1 \mathrm{E}-23$} & & $8 \mathrm{E}-23$ & $4 \mathrm{E}-26$ & $1 \mathrm{E}-28$ \\
\hline No Graft ${ }^{* *}$ & & & & \multicolumn{2}{|c|}{$2 \mathrm{E}-14$} & & $5 \mathrm{E}-8$ & $1 \mathrm{E}-9$ & $4 \mathrm{E}-5$ \\
\hline
\end{tabular}

${ }^{*} \mathrm{p}$ value comparing the category of the graft group to the same category of non-graft group; ${ }^{* *}$ p value comparing the post-operative score to the preoperative score.

${ }^{1}$ 2ccs liquid NuCel ${ }^{\circledR}$, NuTech Medical, Inc., Birmingham, AL. 
graft. At the three year mark, 5 patients in the HAA group and 13 patients in the control group have had revision surgery.

\section{Discussion}

The use of HAA in repairing osteochondral bone tissue has been shown to be an effective treatment in specifically talar dome TCF's less the $2 \mathrm{~cm}^{2}$ in size. A significantly statistical improvement post-operatively was found from the preoperative status between the control group without HAA and the treatment group with HAA. This showed statistically that the graft was beneficial in reducing pain of the area as shown by the visual analog scale as well as the theoretically improved movement and function of the joint indicated by the ACFAS scoring. The greater overall improvement from the averages of the preoperative score to the postoperative scores in the HAA patients than those that underwent surgery without a graft lends support to the use of HAA in osteo-chondral tissue repair. The difference in MRI to intra-operative lesion size is noted and warrants further investigation. The use of MRI pre-operatively is necessary to see the location of the lesion and gauge its size; however the validity of using the MRI as a tool of measurement is questioned. The authors recognize the need for further investigation with double-blind, randomized studies as well as a variety of applications to allow for more broad use of human amniotic allograft. The long-term improvement of the talus bone and the ankle joint with the use of an allograft may also have implications on joints elsewhere in the body. This study as well as other similar studies done may provide a stepping stone to more broad applications using HAA on other bone fracture locations and joints and may prove to be beneficial in supporting tissue healing and improved joint function throughout the body. The authors look forward to longer-term results in these comparison groups in the next 3 to 5 years.

\section{Disclosure}

The authors report no financial gain or conflict of interest with the conducted study.

\section{References}

[1] Kappis, M. (1922) Weitere Beiträge zur Traumatisch-mechanischen Entstehung der “Spontanen” Knorpelablösungen (sog. Osteochondritis dissecans). Deutsche Zeitschrift für Chirurgie, 171, 13-29. http://dx.doi.org/10.1007/BF02812921

[2] Rendu, A. (1932) Fracture intra-articulaireparcellaire de la poûlieastraglienne. Lyon Médical, 150, 220.

[3] Yvars, M.F. (1975) Osteochondral Fractures of the Dome of the Talus. Clinical Orthopaedics and Related Research, 114, 185-191.

[4] Angermann, P. and Jensen, P. (1989) Osteochondritis Dissecans of the Talus: Long-Term Results of Surgical Treatment. Foot \& Ankle, 10, 161-163. http://dx.doi.org/10.1177/107110078901000309

[5] Kelbérine, F. and Frank, A. (1998) Arthroscopic Treatment of Osteochondral Lesions of the Talar Dome: A Retrospective Study of 48 Cases. Arthroscopy: The Journal of Arthroscopic \& Related Surgery: Official Publication of the Arthroscopy Association of North America and the International Arthroscopy Association, 15, 77-84. http://dx.doi.org/10.1053/ar.1999.v15.0150071

[6] Hatch, E.L. (1999) Burns and Bravery. In: Hatch, E.L., Ed., Médico: My Life as a Country Doctor in Mexico, 193-195.

[7] Gwei-Djen, L. and Needham, J. (1964) Medieval Preparations of Urinary Steroid Hormones. International Journal for the History of Medicine, 8, 101-121. http://dx.doi.org/10.1017/S0025727300029355

[8] Davis, S. (1910) Skin Transplantation: With a Review of 550 Cases at the Johns Hopkins Hospital. Johns Hopkins Medical Journal, 15, 307-396.

[9] Sabella, N. (1913) Use of the Fetal Membranes in Skin Grafting. Medication Reconciliation, 83, 478-480.

[10] Stern, M. (1913) The Grafting of Preserved Amniotic Membrane to Burned and Ulcerated Surfaces. Substituting Skin Grafts. JAMA, 60, 973-974. http://dx.doi.org/10.1001/jama.1913.04340130021008

[11] Douglas, B. (1952) Homografts of Fetal Membranes as a Covering for Large Wounds-Especially Those from Burns: An Experimental and Clinical Study (Preliminary Report). Journal of the Tennessee Medical Association, 45, $230-235$.

[12] de Rotth, A. (1940) Plastic Repair of Conjunctival Defects with Fetal Membranes. Archives of Ophthalmology, 23, 522-525. http://dx.doi.org/10.1001/archopht.1940.00860130586006

[13] Shimberg, M. (1938) The Use of Amniotic-Fluid Concentrates in Orthopaedic Conditions. The Journal of Bone \& Joint Surgery, 20, 167-177. 
[14] Trelford, J.D., Hanson, F.W., Anderson, D.C. and Mendel, V.E. (1975) Amnion Autografts, Permanent Structure. Journal of Medicine, 6, 243-247.

[15] Volkov, M.V. (1973) Arthroplasty of Joints Using Amniotic Membrane. In: Chapchal, G., Ed., Arthroplasty of the Hip: 5th International Symposium 1972 in Nijmegen Netherlands, Georg Thieme, Stuttgart.

[16] Anderson, J.J. (2009) Bone Grafting and Orthobiologics for Reconstruction of the Diabetic Lower Extremity. In: Zgonis, T., Ed., Surgical Reconstruction of the Diabetic Foot and Ankle, Lippincott Williams \& Wilkins, Philadelphia, 192-193.

[17] Cornell, C.N. (1999) Osteoconductive Materials and Their Role as Substitutes for Autogenous Bone Grafts. Orthopedic Clinics of North America, 30, 591-598. http://dx.doi.org/10.1016/S0030-5898(05)70112-7

[18] Weinraub, G.M. (2005) Orthobiologics: A Survey of Materials and Techniques. Clinics in Podiatric Medicine and Surgery, 22, 509-519. http://dx.doi.org/10.1016/j.cpm.2005.08.003

[19] Lane, J.M. and Bromstrom, M.P.G. (1998) Bone Grafting and New Composite Biosynthestic Graft Materials. AAOS Instructional Course Lectures, 47, 525-534.

[20] Martin, R.B., Chapman, M.W., Sharkey, N.A., Zissimos, S.L., Bay, B. and Shors, E.G. (1995) Bone Ingrowth and Mechanical Properties of Coralline Hydroxyapatite 1 Year from Implantation. Biomaterials, 14, 341-348. http://dx.doi.org/10.1016/0142-9612(93)90052-4

[21] Anderson, J.J., Boone, J.J., Hansen, M., Brady, C., Gough, A. and Fowler, Z. (2015) Ankle Arthrodesis Fusion Rates for Mesenchymal Stem Cell Bone Allograft versus Proximal Tibia Autograft. The Journal of Foot and Ankle Surgery, 53, 683-686. http://dx.doi.org/10.1053/j.jfas.2014.06.029

[22] Anderson, J.J., Jeppesen, N.S., Hansen, M., Brady, C., Gough, A. and Fowler, Z. (2013) First Metatarsophalangeal Joint Arthrodesis: Comparison of Mesenchymal Stem Cell Allograft versus Autogenous Bone Graft Fusion Rates. Surgical Science, 4, 263-267. http://dx.doi.org/10.4236/ss.2013.45051

[23] Sachs, B.P. and Stern, C.M. (1979) Activity and Characterization of a Low Molecular Fraction Present in Human Amniotic Fluid with Broad Spectrum Antibacterial Activity. BJOG: An International Journal of Obstetrics and Gynaecology, 86, 81-86. http://dx.doi.org/10.1111/j.1471-0528.1979.tb10572.x

[24] Anderson, J.J., Gough, A.F., Hansen, M.H. and Swayzee, Z. (2015) Initial Experience with Tricortical Iliac Crest Bone Graft and Human Amniotic Allograft in Evans Calcaneal Osteotomy. Stem Cell Discovery, 5, 11-17. http://dx.doi.org/10.4236/scd.2015.52002

[25] Anderson, J.J., Hansen, M.H. and Swayzee, Z. (2014) Human Amniotic Allograft in Use on Talar Dome Lesions: A Prospective Report of 37 Patients. Stem Cell Discovery, 5, 55-60. http://dx.doi.org/10.4236/scd.2014.43006

[26] Anderson, J.J. and Hansen, M.H. (2014) Chronic and Refractory Plantar Fasciitis Treatment with Single-Dose Dehydrated Amniotic Allograft Injection. Abstract Poster Presented at: ACFAS Annual Scientific Meeting, Las Vegas, 11-14 February 2014.

[27] Jin, C.Z., Park, S.R., Choi, B.H., Lee, K.-Y., Kang, C.K. and Min, B.-H. (2007) Human Amniotic Membrane as a Delivery Matrix for Articular Cartilage Repair. Tissue Engineering, 13, 693-702. http://dx.doi.org/10.1089/ten.2006.0184

[28] Connor, D. and Tabet, S. (2013) The Use of Human Amniotic Membrane for Cartilage Repair: A Sheep Study. Abstract Presented at: AANA/Metcalf Combined Arthroscopy Surgery Meeting, Sun Valley, 7-10 February 2013.

[29] Davitt, J.S., MacWilliams, B.A. and Armstrong, P.F. (2001) Plantar Pressure and Radiographic Changes after Distal Calcaneal Legthening in Children and Adolescents. Journal of Pediatric Orthopaedics, 21, 70-75. http://dx.doi.org/10.1097/01241398-200101000-00015

[30] NuTech Medical (2012) NuCel: Multipotential Cellular Matrix (HCT/P). 1, 1-2.

[31] NuTech Medical (2012) NuCel: Product Overview. 1, 1-2.

[32] Sato, T.A., Keelan, J.A. and Mitchel, M.D. (2003) Critical Paracrine Interactions between TNF- $\alpha$ and IL-10 Regulate Lipopolysaccharide-Stimulated Human Choriodecidual Cytokine and Prostaglandin $\mathrm{E}_{2}$ Production. The Journal of Immunology, 170, 158-166. http://dx.doi.org/10.4049/jimmunol.170.1.158 